\title{
An Implementation of Real-Time Numeral Recognizer Based on Hand Gesture Using Both Gradient and Positional Information
}

\author{
$\mathrm{Ji}-\mathrm{Ho} \mathrm{Kim}{ }^{+} \cdot$ Yang-Woo Park ${ }^{++} \cdot \mathrm{Kyu}-\mathrm{Phil} \mathrm{Han}{ }^{+++}$
}

\begin{abstract}
An implementation method of real-time numeral recognizer based on gesture is presented in this paper for various information devices. The proposed algorithm steadily captures the motion of a hand on 3D open space with the Kinect sensor. The captured hand motion is simplified with PCA, in order to preserve the trace consistency and to minimize the trace variations due to noises and size changes. In addition, we also propose a new HMM using both the gradient and the positional features of the simplified hand stroke. As the result, the proposed algorithm has robust characteristics to the variations of the size and speed of hand motion. The recognition rate is increased up to $30 \%$, because of this combined model. Experimental results showed that the proposed algorithm gives a high recognition rate about $98 \%$.
\end{abstract}

Keywords : Kinect, Principal Component Analysis, HMM, Numeral Recognition

\section{기울기와 위치 정보를 이용한 손동작기반 실시간 숫자 인식기 구현}

김 지 $\overline{ }^{\dagger} \cdot$ 박 양 우 $^{\dagger+} \cdot$ 한 규 필 ${ }^{+\dagger}$

\section{요 약}

본 논문에서는 다양한 정보단말기에 활용될 수 있는 손동작기반의 실시간 숫자 인식기 구현 기법을 제안한다. 제안한 알고리즘은 키넥트 센 서를 활용하여 3 차원 공간에서 손의 움직임을 획득한다. 획득한 손의 궤적은 잡음과 제스처의 크기 변화에 의한 궤적 변화를 최소화하고 일관 성 있는 추적을 유지하기 위해 주성분 분석으로 단순화 된다. 또한, 기울기와 위치정보 특징을 동시에 고려한 새로운 특징 기반 은닉 마르코프 모델을 제시한다. 그 결과 제안한 기법은 손동작의 크기와 움직임 속도에 강인한 실시간 인식기를 구현하였다. 실험을 통하여 기존의 기울기 정보만을 사용하였을 때 보다 $30 \%$ 이상의 높은 인식률을 보였으며, $98 \%$ 의 높은 숫자 인식률을 나타내었다.

키워드 : 키넥트, 주성분 분석, 은닉 마르코프 모델, 숫자 인식

\section{1. 서 론}

최근 사람과 컴퓨터간의 보다 자연스러운 상호작용을 지 원하기 위해 기존의 입력방식인 키보드, 마우스에서 벗어나 IT기기의 발전과 다양성에 따라 터치스크린, 음성인식, 제스 처 인식 등 많은 방법들이 개발되고 있다[1,2]. 이 중 손동작 은 일상생활에서 사람들 간에 사용되는 주요 상호 작용 수

\footnotetext{
※ 본 연구는 금오공과대학교 학술연구비에 의하여 연구된 논문임.

† 준 회 원: (주)JVM 연구소 연구워

†† 정 회 원: 경운대학교 모바일공학과 교수

††† 정 회 원: 금오공과대학교 컴퓨터공학과 교수

논문접수: 2012년 8월 1일

수 정 일 : 1 차 2012년 10월 8일, 2차 2012년 11월 27일

심사완료 : 2012년 11월 29일

* Corresponding Author:Kyu-Phil Han(kphan@kumoh.ac.kr)
}

단으로 사용되고 있으며, 또한 특별한 장치를 사용하지 않 기 때문에 자연스러운 형태의 인터페이스로 활용될 수 있 다. 따라서 비전시스템에 기반한 손동작 인터페이스의 관심 이 증가하고 있는 추세이다[3-5].

손동작에 관한 연구는 접근 방법에 따라 크게 두 가지로 나뉜다. 첫 번째는 글러브 데이터 기반 방법으로 손과 손가 락에 부착된 센서를 사용하여 손의 움직임을 쉽게 파악한다 [3]. 그러나 이 장치는 가격이 비싸고 센서 장치를 입어야 하는 번거로움이 있다. 두 번째 방법은 영상 기반 방법으로 카메라만을 사용하기 때문에 가격이 비교적 저렴하고 간단 한 장치로 구현할 수 있지만, 배경에서 물체를 구분하기 어 렵고 조명에 영향을 많이 받기 때문에 손동작 분석이 어렵 다는 문제를 가지고 있다[4,5]. 그러므로 본 논문에서는 비전 시스템을 기반으로 하는 동작 인식 인터페이스 시스템을 개 
선하기 위해 적외선 깊이 카메라를 이용한 동작 인식 방법 을 제안하려고 한다.

최근 마이크로소프트사에서는 사용자의 신체를 이용하여 게임과 엔터테인먼트를 경험할 수 있는 XBOX 360의 컨트 롤러인 키넥트 센서(Fig. 1)를 출시하였다. 이 센서는 기존 유무선 컨트롤러 대신 적외선 능동형 센서를 이용하여 사용 자의 동작을 인식하고 컴퓨터와 상호작용을 제어하는 혁신 적인 기술이다[6]. 또한 칼라 $\mathrm{CCD}$ 와 깊이를 획득할 수 있는 적외선 센서 렌즈(colour and depth-sensing lenses)가 내장 되어 있어 스테레오 카메라와 동일한 역할을 한다. 기존의 스테레오 카메라보다 가격이 매우 저렴하고 $30 \mathrm{fps}$ 이상의 깊 이영상획득과 질감사상(texture mapping)을 지원하여 응용 제품 및 프로그램 개발에 어려움이 없다는 장점이 있다.

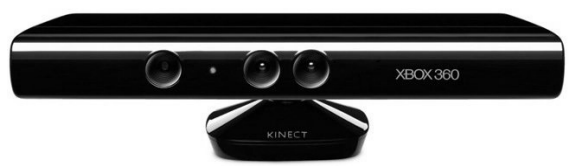

Fig. 1. Kinect sensor

이에 발맞추어 키넥트 센서를 구동하기 위해 원천기술 제 공사인 PrimeSense사가 OpenNI(Open Source Natural Interaction Driver \& $\mathrm{AP}$ )와 미들웨어인 NITE를 공개함으 로써 개발자들이 이 센서를 활용하여 여러 가지 애플리케이 션을 손쉽게 개발하기 시작하였다[7]. Fig. 2는 NITE OpenAPI를 이용하여 손을 추적한 깊이 영상이다.
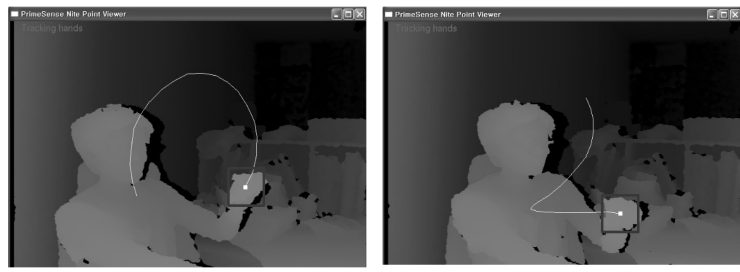

Fig. 2. An example of hand tracking using NITE OpenAPI

\section{2. 관련 연구}

손을 이용한 제스처는 공간적인 정보만을 사용하는 정적 (static) 제스처와 시간적인 정보를 사용하는 동적(dynamic) 제스처로 나눌 수 있다. 정적 제스처를 사용하는 경우, 정의 하는 제스처의 수가 많아질수록 구분할 수 있는 형태의 차 이가 작아지므로 각 제스처를 분류해내기가 어렵다. 반면, 동적 제스처는 정적 제스처에 비해 표현이 자연스럽고 사용 할 수 있는 제스처의 수도 많지만 움직임 중에서 실제로 의 미가 있는 부분을 추출해내기가 어렵다는 단점이 있다[8].

$\operatorname{HMM}$ (Hidden Markov Model)은 동적인 신호 및 이벤트 를 모델화하는데 유용하기 때문에 음성인식과 필기체인식 및 제스처인식 등에 가장 널리 사용되고 있다[9]. HMM을 인식 에 활용하기 위해서는 먼저 제스처 궤적으로부터 특징을 추 출해야 한다. 특징을 추출할 수 있는 방법으로는 크게 두 가
지로 나눌 수 있는데, 하나는 움직임 벡터간의 기울기를 균 일한 영역으로 분류하여 특징코드로 사용하는 방법이고, 또 하나는 제스처 궤적의 전체 영역을 공간적으로 분할해서 위 치 정보를 이용해 특징코드를 생성하는 방법이다[10,11].

카메라를 이용한 손동작 인식은 손의 떨림이나 손 추적 실패로 인해 다양한 오류코드가 발생할 수 있다. 기존 연구 에서는 학습기에 오류코드를 포함하여 학습되지 않은 데이 터가 발생되더라도 데이터의 유사도를 판단하여 인식결과를 나타낸다. 그러나 이러한 방법은 수많은 학습데이터와 그에 따른 학습 모델이 필요하게 되며 인식 결과에도 나쁜 영향 을 미치게 된다. 또한, 같은 움직임의 제스처임에도 사용자 의 움직임 속도, 제스처의 크기 등에 따라 특징코드가 다 르게 된다. 따라서 본 논문에서는 3 차원 공간에서의 손의 움직임 정보를 단순화하여 대표적인 방향 정보 특징을 추출 하고, $\mathrm{HMM}$ 에 적용하였을 때 높은 인식 정확률과 계산 시 간을 감소시키는 방법을 제시한다.

\section{3. 제안한 알고리즘}

제안한 알고리즘은 Fig. 3에서와 같이 키넥트와 NITE를 사용하여 손의 위치를 입력받고 $\mathrm{PCA}$ 를 이용한 궤적 단순 화, 기울기 및 위치 코드를 검출하는 특징 추출, 그리고 $\mathrm{HMM}$ 을 이용한 손동작 인식 3 단계로 나누어진다.

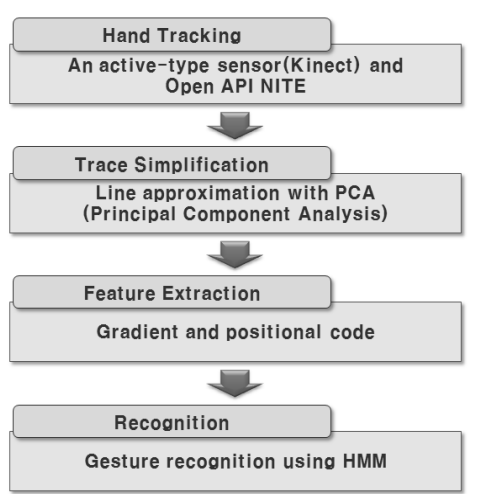

Fig. 3. Block diagram of the proposed algorithm

\section{1 궤적 단순화}

사용자의 움직임 속도, 제스처의 크기, 손 트래킹의 실패 에 의한 잡음 점(outlier)들로 하나의 제스처에서 파생되는 시퀀스는 표현에 따라 수백 개가 될 수 있다. 따라서 비슷 한 방향성을 가지고 있는 시퀀스는 하나의 직선으로 표현해 주는 것이 가장 좋다. 이러한 문제를 제거 또는 완화하기 위해서 제안한 알고리즘에서는 $\mathrm{PCA}$ 를 이용하여 대표적인 직선으로 단순화한다. $\mathrm{PCA}$ 는 전체 영상 데이터를 잘 표현 하는 몇 개의 주성분들의 축(axis)에 데이터를 선형 투영 (linear projection) 시키며[12] 데이터의 차원을 감소시키고 잡음을 제거하는 효과가 있다[13]. Fig. 4는 PCA 과정 예를 보여준다. 


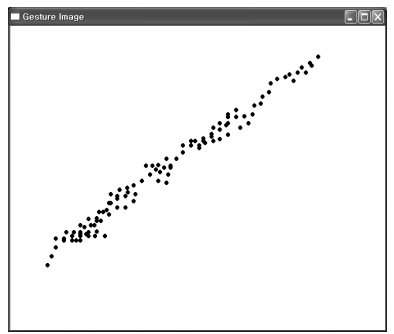

(a) data

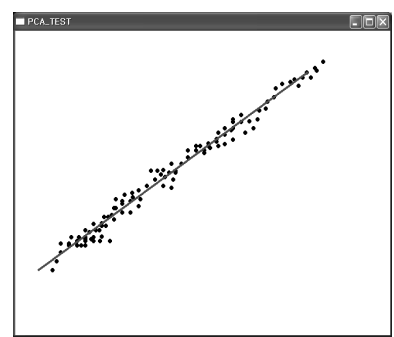

(b) PCA line
Fig. 4. A PCA example

제안한 방식에서 손의 궤적을 획득할 때, $1 / 3$ 초 동안 손 의 움직임이 발생되지 않으면 무의미한 구간으로 구분하였 고 간단한 전처리 과정을 거친다. 의미있는 구간으로 판단 되어 획득된 손의 위치들에서 중심점을 계산한 후, 이 중심 점에서 최대 거리의 $10 \%$ 를 문턱치로 설정하여 인접한 손의 움직임이 동일 직선상에 있고 이동거리가 문턱치 이하면 가 장 가까운 점으로 병합시킨다. 문턱치를 손 궤적의 중심점 에서 가장 먼 궤적까지의 거리에 $10 \%$ 로 설정한 이유는 숫 자를 허공에 입력할 때, 최대 2초정도 소요되고 프레임율이 $18 \mathrm{fps}$ 이므로 보통 40개 미만의 손 위치가 획득된다. 이는 특 징으로 사용하기에 많은 양이므로 최대 15 개이하로 줄이기 위해 실험적으로 선택한 값이다.

초기 전처리 간소화 과정을 거친 후, 전체 손의 궤적을 여러 개의 대표 직선으로 모델링하기 위해서는 점들이 분리 (split)되어야 한다. 초기 PCA 근사 직선은 Fig. 5의 첫 번 째 행과 같이 손 궤적의 첫 번째 점과 마지막 점을 연결한 직선이 된다. 초기 근사 직선에서 가장 큰 투영거리를 갖는 점(Fig. 5의 두 번째 행)을 기준으로 전후 점들의 집합으로 이진 분리된다. 이 초기 최대 투영거리의 $10 \%$ 를 새로운 문 턱치로 설정하여 각 점 집합에서 투영거리가 문턱치 이하가 될 때까지 반복 분리되며 투영거리가 작은 점은 제거된다. Fig. 6에 각 숫자별 $\mathrm{PCA}$ 를 적용한 단순화 결과를 나타내었 으며, 궤적을 $\mathrm{PCA}$ 로 단순화함으로써 잡음과 미세 이동점들 이 제거되며, 최소한의 좌표정보만으로 궤적 시퀀스의 표현 이 가능해진다. Fig. 7은 비슷한 제스처의 경우, 크기에 상 관없이 유사한 시퀀스를 얻을 수 있음을 보여주고 있다.

\section{2 특징 추출}

인식을 수행하기 위해서는 제스처 궤적에서 특징을 추출 해야 한다. 제안한 기법에서는 두 가지 특징을 생성하게 되 는데, 첫 번째 특징은 Fig. 8과 같이 360도 기울기를 8방향 으로 균일하게 나누어 궤적 직선의 기울기 정보를 생성한 다. 두 번째로는 Fig. 9와 같이 손 궤적이 포함된 공간을 9 개의 부영역(sub-region)으로 나누어 위치기반 특징을 생성 한다. 이 때, 전체 영역의 사각형은 궤적의 중심좌표에서 가 장 먼 좌표까지의 거리를 상하좌우 방향의 폭으로 설정하였 으며, 궤적 진행에 따라 부영역의 위치가 바뀌는 순서를 특 징으로 이용한다.

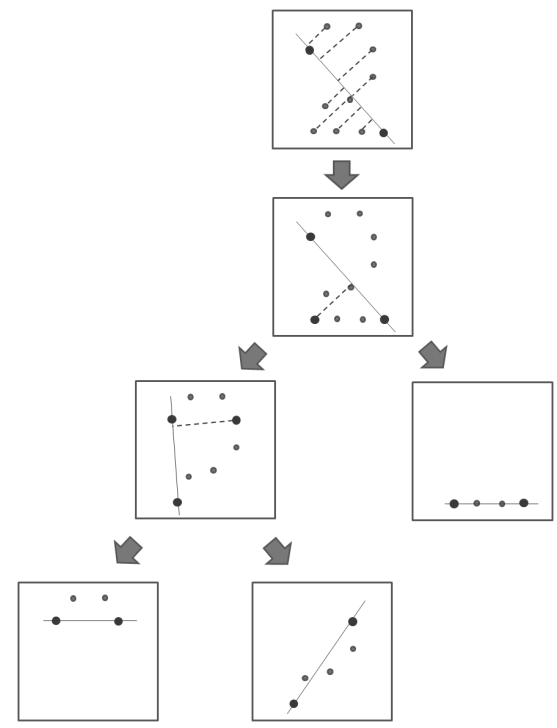

Fig. 5. An interval division for '2'

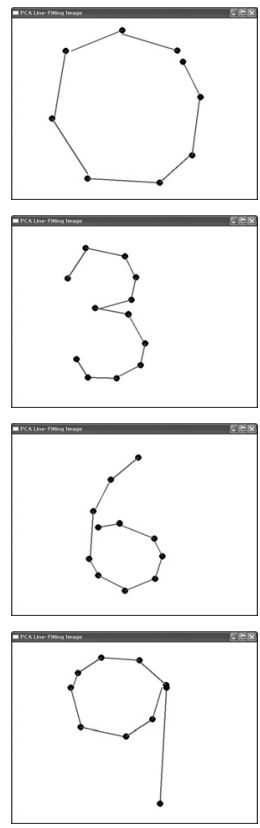

Fig. 6. The proposed PCA approximation for numeral letters

기울기와 위치기반 특징을 동시에 고려하는 것은 인식의 성능을 높이기 위함이다. 왜냐하면 원을 포함하는 숫자 0 , 6,9 는 다른 위치기반 특징을 가지지만, 매우 비슷한 기울기 특징을 가지기 때문이다. Table 1은 숫자 0에 대해서 8방향 기울기 특징만을 사용하여 100 개의 시험 자료에 적용한 인 식결과이다. 각각의 학습 데이터를 분석한 결과 $0,6,9$ 는 기울기 특징이 매우 유사한 방향으로 진행되는 것을 알 수 있었으며, 특히 0과 6은 Fig. 10에서와 같이 손의 진행방향 이 비슷하면 기울기 코드가 동일하여 구분하지 못하는 문 제점이 발생하게 된다.[11] 따라서 Fig. 11과 같이 위치정보 를 특징으로 사용하여 기울기 영역 특징의 단점을 보완하 도록 하였다. 


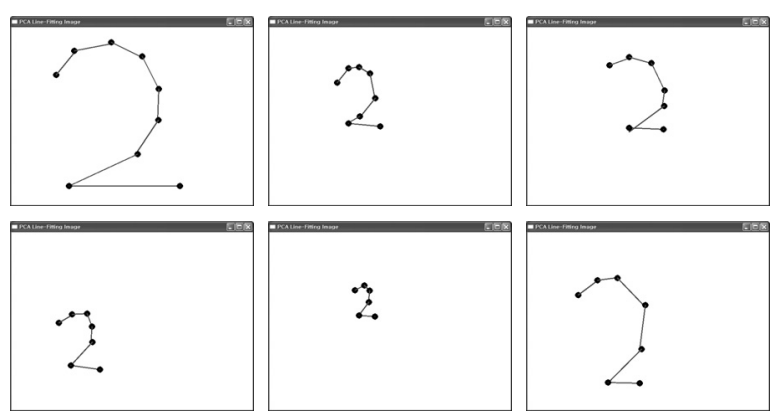

Fig. 7. Similar sequence with different size

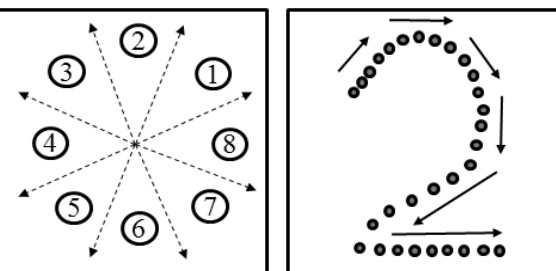

Fig. 8. Gradient-based feature code

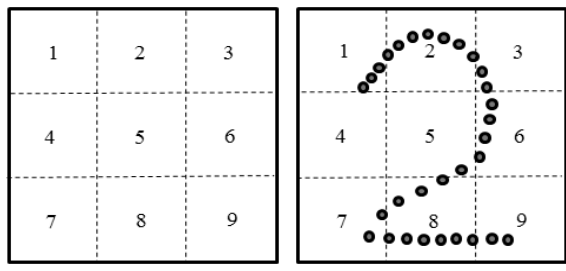

Fig. 9. Position-based feature code

Table 1. A recognition result for numeral cursive ' 0 ' using only 8-gradient feature

\begin{tabular}{c|c|c|c|c|c|c|c|c|c|c}
\hline Output & 0 & 1 & 2 & 3 & 4 & 5 & 6 & 7 & 8 & 9 \\
\hline $\begin{array}{c}\text { Recognition } \\
\text { result[\%] }\end{array}$ & 64 & 0 & 0 & 0 & 0 & 0 & 29 & 0 & 0 & 7 \\
\hline
\end{tabular}

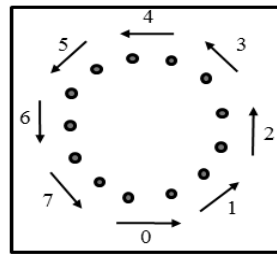

(a) $5-6-7-0-1-2-3-4$

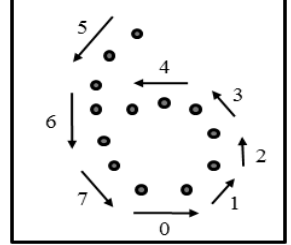

(b) $5-6-7-0-1-2-3-4$
Fig. 10. The same directional code (a) ' 0 ' (b) ' 6 '

\section{3 $\mathrm{HMM}$ 을 이용한 손동작 인식}

$\mathrm{HMM}$ 은 확률에 따른 패턴의 일련을 수학적으로 모델링 하여 최적의 관측을 할 수 있기 때문에 음성인식 및 형태소 분석 등 다양한 시스템에 활용되고 있다[14]. HMM은 상태 (state)라 불리는 노드와 이들 간의 천이를 나타내는 선분으 로 구성된 그래프로 표현될 수 있으며, 그래프의 각 노드에 는 공간적인 특성을 모델링하는 관측 심볼의 확률 분포와
초기 상태 확률 분포가 저장되어 있으며, 각 선분에는 관측 열의 시간적인 특성을 모델링하는 상태 천이 확률 분포가 저장되어 있다[15,16].

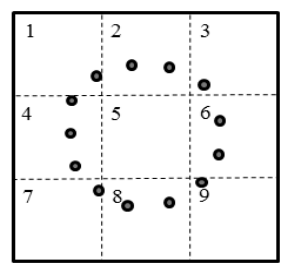

(a) 2-1-4-7-8-9-6-3-2

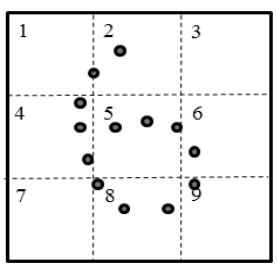

(b) $2-4-8-9-6-5$
Fig. 11. Different positional codes (a) ' 0 ' (b) ' 6 '

일반적으로 $\mathrm{HMM}$ 은 모델 파라미터 $\lambda=(A, B, \pi)$ 로 표현 되며 표기는 아래와 같다.

$\square$ State set : $S=\left\{S_{1}, S_{2}, \ldots, S_{N}\right\}, N=$ number of states

$\square$ Observable set : $V=\left\{v_{1}, v_{2}, \ldots ., v_{M}\right\}$, $M=$ number of observable symbols

$\square$ State of observation at time $t: q_{t}$

$\square$ Probability of transition from state $i$ to $j$ :

$$
a_{i j}=P\left(q_{t+1}=S_{j} \mid q_{t}=S_{i}\right), 1 \leq i, j \leq N
$$

$\square$ Probability distribution of state transitions : $A=\left\{a_{i j}\right\}$

$\square$ Probability of occurring $k$-th observation from $j$-th state:

$$
b_{j}(k)=P\left(v_{k} \mid q_{t}=S_{j}\right), 1 \leq j \leq N, 1 \leq k \leq M
$$

$\square$ Probability distribution of observation symbols : $B=\left\{b_{j}(k)\right\}$

$\square$ Probability distribution of initial states:

$$
\pi=\left\{\pi_{i}\right\}, \pi_{i}=P\left(q_{1}=S_{i}\right), 1 \leq i \leq N
$$

생성된 모델과 관측열 $O=\left(O_{1}, O_{2}, \ldots, O_{t}\right)$ 에 대한 생성확 률은 다음과 같다.

$$
P(O \mid \lambda)=\sum_{\text {for allq }}\left[\pi_{q_{1}} b_{q_{1}}\left(O_{1}\right) \prod_{i=2}^{t}=a_{q_{i-1} q_{i}} b_{q_{i}}\left(O_{i}\right)\right]
$$

본 연구에서는 모델링에 있어서 단순하고 인식분야에 많 이 사용되는 Left-Right $\mathrm{HMM}$ 구조를 채택하였고, 최종적으 로 Fig. 12 와 같이 기울기기반 및 위치기반 $\mathrm{HMM}$ 을 각각 생성하고 이를 가중치 결합한 인식기를 제시한다. 최종적인 인식확률값 $\left(P_{F}\right)$ 은 아래와 같다.

$$
P_{F}=\omega_{G} \times P_{G}+\omega_{P} \times P_{P}
$$

여기서 $\omega_{G}$ 와 $\omega_{P}, P_{G}$ 와 $P_{P}$ 는 기울기기반과 위치기반의 가중치와 인식 확률값을 의미한다. 본 논문에서는 $\omega_{G}=0.6$, $\omega_{P}=0.4$ 로 설정하였다. 왜냐하면 $P_{P}$ 의 숫자별 inter-class 및 


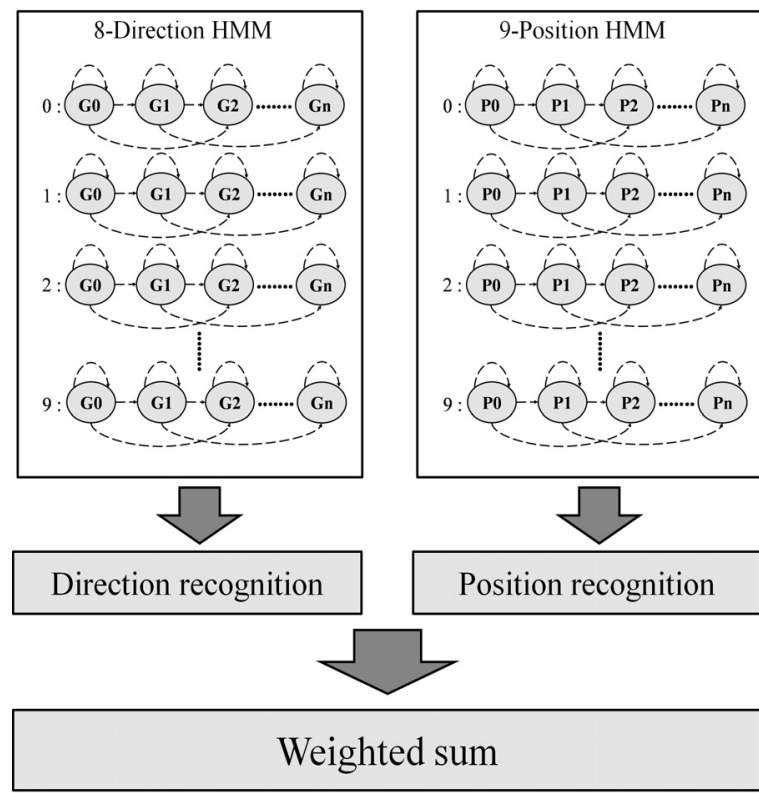

Fig. 12. Gradient and positional HMM of the proposed scheme

숫자간 intra-class 분산 평균값이 $P_{G}$ 보다 1.5 배 크게 나타 났기 때문이다.

\section{4. 실험 결과}

제안한 인식 시스템을 0-9까지 손동작 필기체 숫자에 대 해 적용하였고 실험에 사용된 컴퓨터는 Intel(R) Core(TM)2 Quad CPU 2.40GHz이며 영상 입력장치로는 키넥트 센서를 사용하였다. 카메라를 통해 입력된 영상의 해상도는 $640 \times 480$ 화소이며 frame rate는 $18 \mathrm{fps}$ 를 사용하였다. Fig. 13은 손의 움직임을 추적하여 궤적을 표시한 영상이다. 학 습과 테스트 제스처는 각각 100 개씩 사용하였고 무작위로 선택한 10명에게 특별한 정보를 제공하지 않고 0-9까지의 수를 2번씩 입력하도록 하여 학습과 테스트 제스처로 각각 사용하였다. Table 2에 각 숫자별 인식률을 나타내었으며, 제안한 방법은 평균 $98.4 \%$ 의 인식 정확도를 보여주었다. 여 기에서 no decision은 손의 움짐임을 추적하는 과정에서 무 의미한 손 동작을 구분하기 위해서 Fig. 12 에서 보는 것과 같이 9 개의 8 방향 기울기 기반 $\mathrm{HMM}$ 과 9 개의 위치 기반 $\mathrm{HMM}$ 에서 상태 천이 확률이 0.01 이하가 한번이라도 발생되 면 무의미한 손 동작이라고 판단하였다. Fig. 14는 허공에 숫자를 쓰기 때문에 입력자가 신중하지 않게 입력한 경우 오인식되는 예를 보여준다. 특히, 0 과 4 를 입력했을 때 6 과 9 로 오인식되는 경우가 각각 1건 및 2건으로 나타났으며, Fig. 14의 (a)처럼 0을 입력할 때 마지막 궤적이 시작점보다 아래에서 종료되면 6 을 입력한 것과 유사하고 (b)처럼 4 를 입력할 때, 마지막 직선 궤적이 오른쪽으로 치우치면 9 와 매우 유사한 형태가 된다. 이는 blind testing을 하였기 때문 에 나타난 결과이며, 실험자에게 Fig. 14와 같이 혼돈되기
쉬운 방향의 숫자에 대한 정보를 제공하여 시작점에서부터 끝점까지 유사한 방향성과 위치가 보장된다면 상당히 높은 인식률을 얻을 수 있다는 것을 실험을 통해 알 수 있었다. Table 3은 HMM외에 인식에 많이 활용되는 DTW (Dynamic Time Warping)[17]와 DBN(Deep Boltzmann Machine)[18]을 사용한 결과이다. DTW는 원과 같이 점진적 으로 변화되는 방향성을 포함하는 숫자에 대해서 높은 인식 률을 보였으며, $\mathrm{DBN}$ 은 평균적으로 고른 인식률을 보였다.

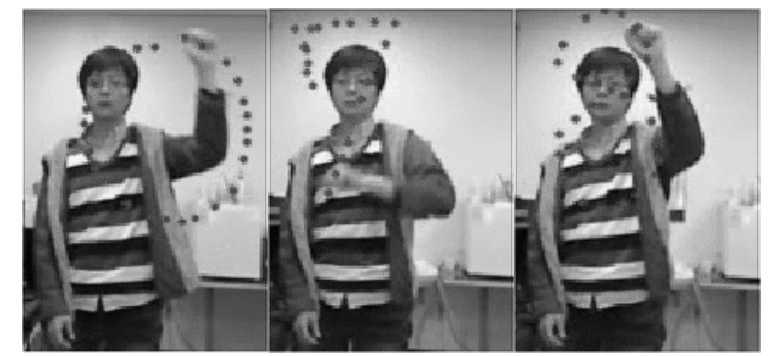

Fig. 13. Hand tracking images of the proposed algorithm

Table 2. Experimental results of the proposed algorithm

\begin{tabular}{c|c|c|c|c|c|c|c|c|c|c|c}
\hline $\begin{array}{r}\text { Result } \\
\text { Input }\end{array}$ & 0 & 1 & 2 & 3 & 4 & 5 & 6 & 7 & 8 & 9 & $\begin{array}{c}\text { No } \\
\text { decision }\end{array}$ \\
\hline \hline 0 & 98 & - & 1 & - & - & - & 1 & - & - & - & - \\
\hline 1 & - & 99 & 1 & - & - & - & - & - & - & - & - \\
\hline 2 & - & - & 100 & - & - & - & - & - & - & - & - \\
\hline 3 & - & - & 1 & 97 & - & - & - & - & - & - & 2 \\
\hline 4 & - & - & - & - & 98 & - & - & - & - & 2 & \\
\hline 5 & - & - & - & - & - & 97 & - & - & 1 & - & 2 \\
\hline 6 & - & - & - & - & - & - & 100 & - & - & - & - \\
\hline 7 & - & - & - & - & - & - & - & 97 & - & 1 & 2 \\
\hline 8 & - & - & - & - & - & - & - & - & 100 & - & - \\
\hline 9 & - & - & - & - & - & - & - & - & - & 98 & 2 \\
\hline
\end{tabular}

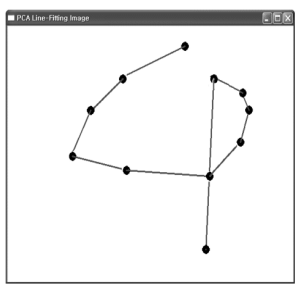

(a) input:4, result:9

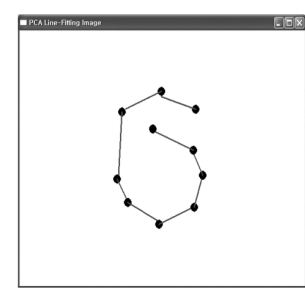

(b) input:0, result 6
Fig. 14. Recognition errors

Table 3. Comparison results with conventional algorithms

\begin{tabular}{c|c|c|c|c|c|c|c|c|c|c|c}
\hline Output & 0 & 1 & 2 & 3 & 4 & 5 & 6 & 7 & 8 & 9 & Aver. \\
\hline \hline DTW & 99 & 98 & 100 & 100 & 97 & 96 & 100 & 95 & 100 & 98 & 98.30 \\
\hline DBN & 98 & 100 & 99 & 99 & 97 & 97 & 99 & 98 & 99 & 98 & 98.40 \\
\hline Proposed & 98 & 99 & 100 & 97 & 98 & 97 & 100 & 97 & 100 & 98 & 98.40 \\
\hline
\end{tabular}




\section{5. 결 론}

본 논문에서는 키넥트 센서를 이용하여 적외선 깊이 영상 을 획득하고 손의 궤적을 추적하여 숫자 인식을 하는 실시 간 숫자 입력기법을 제안하였다. 기존의 모션센서를 이용하 는 방식과는 달리 센서를 소지하지 않아도 되며, 영상기반 의 방식에서의 깊이 또는 손 검출 과정의 속도와 성능저하 를 키넥트 채택으로 개선하였다. 또한 검출된 손의 궤적을 단순화하여 손 궤적의 크기 변화 및 잡음에 대응하였다. 마 지막으로 궤적의 이동 방향 정보인 기울기성분뿐만 아니라 정규화된 공간에서 손의 위치정보를 동시에 고려하여 인식 률을 높였다. 제안된 제스처 기반의 인식 인터페이스는 기 존의 입력방식에 비하여 편리하고 직관적이기 때문에 사용 자와 컴퓨터의 상호작용에 있어서 앞으로 다양한 환경에서 사용될 것으로 예상된다. 향후 과제로는 필기체 영문자 인 식에 적용하여 제스처기반 영문 입력기를 완성할 계획이다.

\section{참 고 문 헌}

[1] D. Hong, W. Woo, "Recent Research Trend of Gesture-based User Interfaces," Telecommunications Review, Vol.18, No.3, pp.403-413, 2008.

[2] A. Sears, J. Feng, K. Oseitutu, and C.-M. Karat, "Hands-Free, Speech-Based Navigation During Dictation: Difficulties, Consequences, and Solutions," Human-Computer Interaction Journal, Vol.18, No.3, pp.229-257, 2003.

[3] D. J. Sturman and D. Zeltzer, "A Survey of Glove-based Input," IEEE Computer Graphics and Applications, Vol.14, No.1, pp.30-39, 1994.

[4] T. B. Moeslund and E. Granum, "A Survey of Computer Vision-Based Human Motion Capture," Computer Vision and Image Understanding, Vol.81, No.3, pp.231-268, 2001.

[5] J. Yun, C. Lee, "Design of Computer Vision Interface by Recognizing Hand Motion,” Journal of IEEK, Vol.47, No.3, pp.256-265, 2010.

[6] http://www.xbox.com/ko-KR/Kinect

[7] http://www.openni.org/

[8] Y. Jang, J. Park, “A Development on Gesture Recognition Interface System and Non-Contact Mouse Device Using a Stereo Camera," Journal of KIIT, Vol.7 No.3, pp.244-252, 2009.

[9] L. R. Rabiner, "A Tutorial on Hidden Markov Models and Selected Applications in Speech Recognition," Proceedings of the IEEE, Vol.77, No.2, pp.257-286, Feb., 1989.

[10] M. Elmezain, A. Al-Hamadi, B. Michaelis, "Hand Trajectory-based Gesture Spotting and Recognition Using HMM,” IESK Conference, pp.3577-3580, 2009.

[11] H. Yoon, J. Soh, B. Min, "Alphabetical Gesture Recognition using HMM,” KIISE, Vol.25, No.2, pp.384-386, 1998.
[12] A. Weingessel and K. Hornik, "Local PCA Algorithms," IEEE Transactions on Neural Networks, Vol.11, No.6, pp.1242-1250, Nov., 2000.

[13] A. M. Martinez and A. C. Kak, "PCA versus LDA", IEEE Trans. on PAMI, Vol.23, No.2, pp.228-233, Feb., 2001.

[14] H. Lee, J. Kim, "An HMM-based threshold model approach for gesture recognition," IEEE Trans. on PAMI, Vol.21, pp.961-973, 1999.

[15] D. Kim, J. Song, and D. Kim, "Simultaneous Gesture Segmentation and Recognition Based on Forward Spotting Accumlative HMMs," Pattern Recognition, Vol.40, pp.3012 3026, 2007.

[16] T. Wakahara and H. Murase, "On-Line Handwriting Recognition," Proceedings of the IEEE, Vol.80, No.7, pp.1181-1194, July, 1992.

[17] http://web.mit.edu/ rsalakhu/www/DBM.html, Matlab source code provided by Ruslan Salakhutdinov

[18] http://www.ee.columbia.edu/ dpwe/resources/matlab/dtw/, Matlab source code provided by Dan Ellis

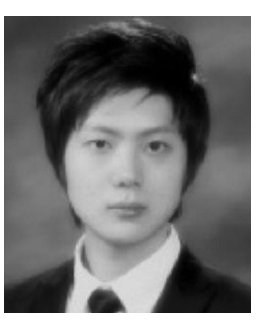

\section{김 지 호}

e-mail : nice@kumoh.ac.kr

2010년 금오공과대학교 컴퓨터공학과(학사) 2012년 금오공과대학교 컴퓨터공학과(석사) 2012년 현 재 (주JVM 연구원 관심분야: 영상처리, 컴퓨터비전 및 그래픽스, 가상현실

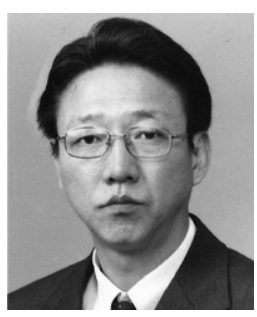

박 양 우 e-mail :ywpark@ikw.ac.kr 1988년 경북대학교 전자공학과(학사) 1990년 경북대학교 전자공학과(석사) 2000년 경북대학교 전자공학과(박사) 1997년 현 재 경운대학교 모바일공학과 교수

관심분야: 디지털컬러영상처리, 자료구조, 알고리즘

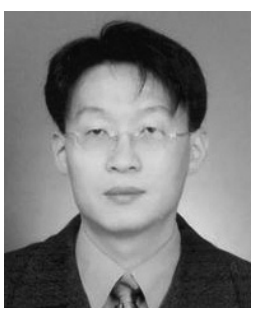

\section{한 규 필}

e-mail : kphan@kumoh.ac.kr 1993년 경북대학교 전자공학과(학사) 1995년 경북대학교 전자공학과(석사) 1999년 경북대학교 전자공학과(박사) 2000년 현 재 금오공과대학교 컴퓨터 공학과 교수

관심분야:DSP, 영상처리, 컴퓨터비전 및 그래픽스, 가상현실 